Article

\title{
Mobile Apps for Green Food Practices and the Role for Consumers: A Case Study on Dining Out Practices with Chinese and Dutch Young Consumers
}

\author{
Wenjuan Mu ${ }^{1,2, *}$, Gert Spaargaren ${ }^{2} \mathbb{D}$ and Alfons Oude Lansink ${ }^{1}$ \\ 1 Business Economics Group, Wageningen University, P.O. 8130, 6700 EW Wageningen, The Netherlands; \\ alfons.oudelansink@wur.nl \\ 2 Environmental Policy Group, Wageningen University, P.O. Box 8130, 6700 EW Wageningen, \\ The Netherlands; gert.spaargaren@wur.nl \\ * Correspondence: wenjuan.mu@wur.nl; Tel.: +31-317-483-882
}

Received: 22 January 2019; Accepted: 22 February 2019; Published: 28 February 2019

check for updates

\begin{abstract}
Mobile applications (apps) have become popular among consumers to facilitate their existing food practices like cooking, shopping, and dining out. However, the feasibility of using mobile apps to facilitate sustainability transitions in food consumption is not well researched. In this study, we, therefore, propose a conceptual framework to illustrate how mobile apps can be developed in linking everyday food practices with sustainability transitions. Through the case study of dining out and with the help of focus group discussions, we seek to illustrate that practice theory might serve as a useful starting point for understanding the dynamics of food practices, their relevant sustainability dimensions, and the ways in which mobile apps can be used for changing current food practices into more sustainable ones. Among our main results are the findings that consumers prefer the sustainability food app to be integrated with dominant or mainstream apps, which are already used by consumers in the context of dining out. Besides being simple, functional, flexible, and rewarding, the information provided by the app should be reliable and trustworthy. Moreover, both science-based and practice-based information is necessary to provide sufficient guidance to consumers on how changes in food practice can be operationalized and implemented.
\end{abstract}

Keywords: food practices; practice theory; sustainability; mobile applications; transitions; consumption

\section{Introduction}

As a crucial part of the earth socio-ecosystem, the current food system is in need of transitions towards a circular, low carbon, and bio-based system [1]. Although many studies have been done with a focus on improving the efficiency of food supply processes, it has been pinpointed that improvements toward the consumption side should be complemented to realize those food transitions toward improving overall sustainability of the food system [2,3].

The food products that consumers buy and the way they transport, store, prepare, and dispose them have a big influence on the overall sustainability of the food system. The consumption-end transition is inevitable for facilitating the food system in becoming more sustainable [4]. How to make the consumption-end transition accepted by consumers is a key research question that should be addressed by the food sector $[1,5]$. However, this is not an easy task. Although extensive science-based knowledge on sustainability has been developed in the food sector, simply educating consumers with this knowledge does not suffice to alter consumers' routinized food behavior in everyday life. Next to being too technical and sometimes controversial, expert knowledge on sustainable and healthy food does not show an easy fit with the lifestyles and existing consumption patterns of modern consumers [1]. 
Research on consumer behavior so far has shown that consumers' behavior is difficult to change since it is highly routinized and taken for granted most of the time [6]. Conventionally, research and policy strategies on changing consumer behavior have been designed from either an individualist or a systemic approach. However, neither approach works effectively. The individualist approach tends to underestimate the impact of context and the important role of routines and habits in shaping everyday life consumption behaviors. The so called 'value-action' gap shows the pitfall of the individualist approach [2]. For example, people who expressed positive attitudes toward the environment do not act accordingly [7]. At the same time, the systemic approach overlooks the importance of consumers as change agents since consumers are more or less forced to change without being involved in the co-designing process. Many innovations developed within the systemic approach in the end failed since they were not properly adopted and used by consumers [2]. As an alternative to the individualist and the systemic approaches, the social practices approach, which is derived from structuration theory, has been suggested. This approach allows for a co-shaping role of the consumers while taking into consideration both the agency of consumers and the context of their actions [8-10]. By taking ordinary, everyday life food practices as the center units of analysis, we are able to better research and understand the elements and patterns in those practices, and come up with feasible socio-technical innovations to make them more sustainable [11]. An emphasis on everyday life social practices will also make it easier for consumers to envision, discuss, and assess the most relevant changes in the production and consumption of food.

The ongoing digitization of society has an enormous impact on consumers' practices [12-14]. Digitalization of social practices has appeared as a clear trend affecting the nearby future in many different and profound ways [12]. Smartphones, for example, have become commonplace and digital terminals exist that empower consumers to an unprecedented extent. Consumers use mobile applications (apps) to conduct a wide range of activities. With respect to food consumption, mobile apps could combine several functions such as access to the most up-to-date information on a series of relevant factors involved in organizing food practices like shopping for food or home cooking. Apps are instrumental for checking the existing labels for particular foodstuff and for communicating about lifestyle, food, and health issues with members of relevant social networks [15]. Mobile apps are, therefore, expected to play a key role in the transition of consumer food practices and to contribute to the overall sustainability of food [16]. Attempts have already been made to raise sustainable awareness and behaviors by using mobile apps. For example, there are mobile apps targeting practices of food waste management (e.g., Too Good To Go), practices of searching for and sharing local food (e.g., Locavore), etc. Nevertheless, according to our knowledge, no conceptual study has been done on ways to integrates the use of mobile apps in efforts to engage consumers with sustainability transitions in everyday life food practices.

This study aims to assess the feasibility of using mobile apps to facilitate the consumption-end sustainable transitions of food practices and explore the role of consumers in it. We start by developing the conceptual framework that illustrates how mobile app interventions can be applied in linking everyday food practices with sustainability issues effectively. The social practice of 'dining out' [17] is selected as a case example to further elaborate the framework. Focus group discussions with consumers are conducted to further validate the conceptual framework, and to pinpoint future directions for the development of mobile apps for food consumers. Last but not least, we discuss the innovation of this study compared to the previous literature, as well as the future perspectives and challenges of using mobile apps for consumers co-constructing more sustainable food systems.

\section{The Conceptual Framework}

A generic conceptual framework is developed to illustrate how mobile-apps-based interventions and forms of co-construction can be used to facilitate sustainability transitions in food practices (see Figure 1). The proposed framework was built based on the inventory of existing research in the fields of food sustainability, food practices, and food apps development. Based on the literature study, 
the emerging role of mobile apps in co-constructing sustainability transitions in food practices was identified and the key question is how to make mobile apps attractive to consumers by understanding and analyzing their food practices and relevant sustainability issues within the different food practices. Relevant literature used in constructing the conceptual framework will be discussed along with the explanation of the framework. In addition to the literature study, the framework was further developed and validated by interviewing experts in the previously mentioned fields as well as presenting in two symposiums of improving resource use efficiency in food systems, where feedbacks are collected and implemented in the final version presented here.

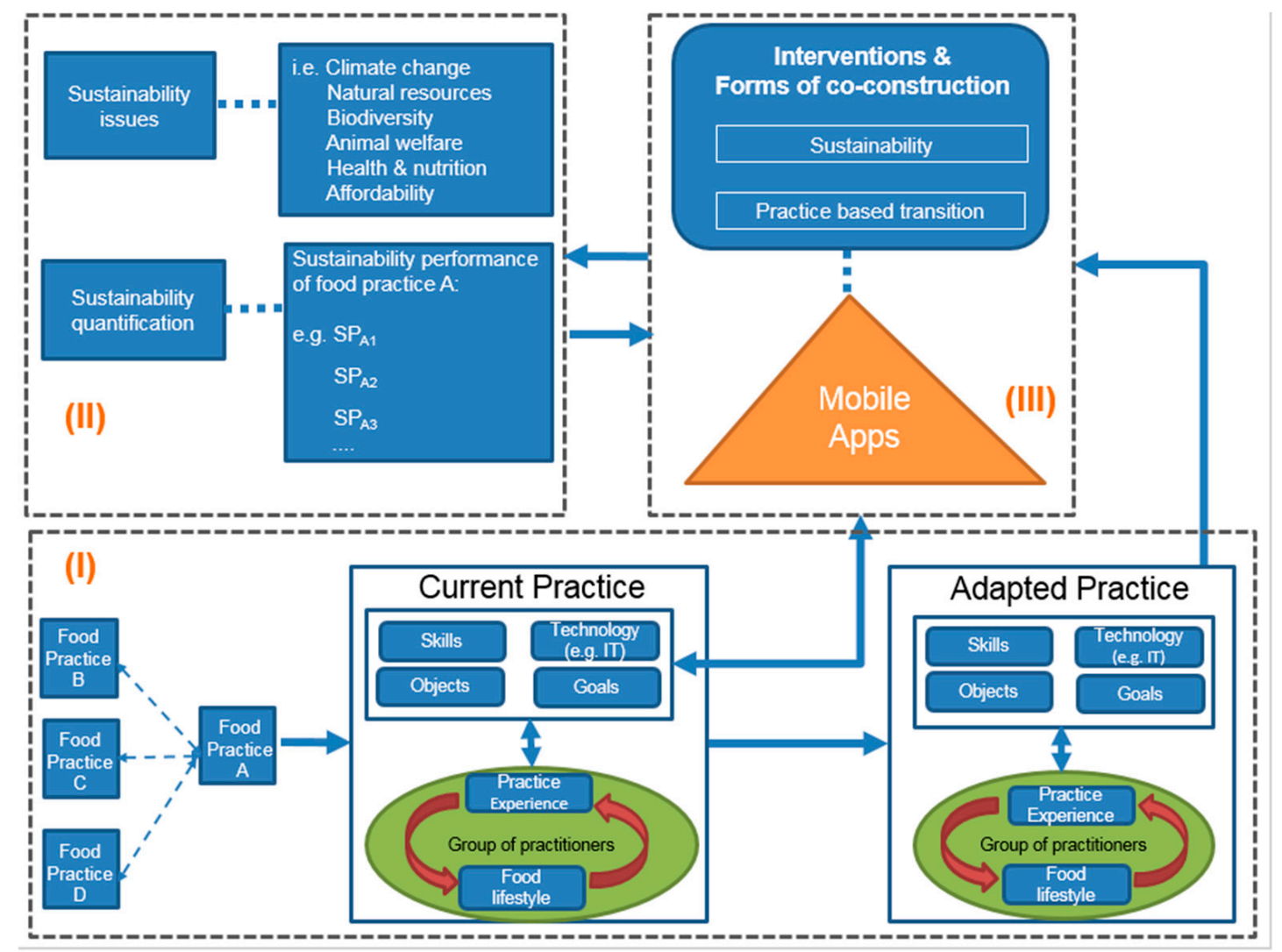

Figure 1. Conceptual framework for studying mobile-apps-based forms of intervention and co-construction for more sustainability food practices.

The framework consists of three sections: (I) identification and description of food practices (see Section 2.1), (II) identification of sustainability issues in food practices (see Section 2.2), and (III) the role of mobile apps as interventions and instruments for co-constructing sustainability transitions in food practices (see Section 2.3). In this framework, we perceive mobile apps as the appropriate device for connecting food practices with sustainability issues and consumer behaviors. In the following sections, we use the practice of dining out to discuss the conceptual framework in detail.

\subsection{Identification and Description of Food Practices}

Identification and description of food practices are illustrated in Figure 1 (box I). Dining out was identified as the case-study practice (i.e., food practice $A$ ) because of its increasing popularity and the significant variations in the performances of dining out between countries and classes [18-20]. While studying the dining out practice, we should be aware that the practice cannot be studied in isolation, but incorporating simultaneously its relations and interactions with other food practices (i.e., food practice $B, C, D$ ) e.g., shopping for food, home cooking. 
A practice does not only consist of a group of practitioners (e.g., consumers) but also skills, objects, technologies, and goals, which jointly co-shape the practice [2]. Skills refer to the knowledge and competences that are needed to conduct the practice. In case of dining out, the skills can be e.g., the knowledge on how to find a suitable restaurant, or how to make payments as a group. Objects represent the materials and infrastructures involved in performing the practice. In the case of dining out, relevant objects are the furniture, tableware, the menu, and dishes. Technologies used in the context of dining out can be e.g., the digital devices for ordering food or creating particular food experiences. Goals represent the social and symbolic meaning of the practice. Originating from a search for convenience and utility, currently, the motivation for dining out are linked with pleasure, leisure, and social networking [21]. Dining out now means often more than just a meal for individuals and is more of an experience (e.g., relaxing with family and friends, being served, trying out new cuisine) that individuals are seeking [22]. Dining out in restaurants, for example, is often seen as an escape from routine activities and has the intention to seek an extraordinary experience [23].

Next to the characteristic elements of the social practice of dining out, we have to specify the practice for its time-space characteristics. The venue for dining out can be roughly categorized into three types, commercial (e.g., restaurants, cafeterias, fast food outlets, snack bars), institutional (e.g., school or work canteens, hospital), and non-commercial (e.g., family or friend's home) [20]. Different aspects can be used to evaluate the experience, such as accessibility of the eating establishments, the interaction between staff and customers, the setting for the meal, the food and beverages, and the atmosphere [21]. Dining out can be either done alone or with other people, but even in the case of eating alone, diners may still be surrounded by other people [22]. The time duration for dining out is different. It can range from less than an hour for lunches at e.g., a cafeteria, to several hours for dinners at a restaurant. Normally, the menu choice is rather fixed, so that orders can only be placed based on what is available on the menu. The spending on the meal can be from several Euros for a lunch bite at a cafeteria up to dozens or even hundreds of euros in a fine restaurant. In this study, we set the practice boundary of dining out as eating in a regular, commercial restaurant.

The relationship between the group of practitioners (i.e., consumers in this study) and the other elements of the practice (i.e., skills, objects and technologies, and goals) is dynamic, and they co-shape each other when performing the practice. In addition, the way in which a specific group of practitioners is performing a food practice, is influenced by their previous experiences with similar practices. These former experiences are stored into their particular lifestyle-for-food [24]. Since the food lifestyle has a long-term experience and character-based nature, it cannot be directly altered in the short term. What can be influenced in the short term are the situated practice experiences occurring in the presence. Especially the "locale" or site of the social practice can be shown to have a direct impact on the ways practices are enacted and experienced. Taking the practice of dining out for example, the waitresses and chefs, the furniture and tableware, the food presentation strategies, the lights, and the temperature all affect the dining-out experience of the consumers in the restaurants. The longer term 'food lifestyle' of practitioners also impacts situated dining out experiences in a sometimes direct and visible way. Some vegetarians are keen in expressing their restricted room for enjoying food in a steakhouse designed to serve meat eaters in particular. In this framework, we only address the food-related segments of the lifestyle of practitioners. We do realize that food-related segments of the lifestyle of an individual can deviate from the other segments and, thereby, the overall lifestyle of the individual. For example, a vegetarian with a dark green segment for food can be fond of frequently traveling the world by plane.

\subsection{Identification of Sustainability Issues in Food Practices}

Identification of sustainability issues in food practices is illustrated in Figure 1 (box II). Sustainability issues for the practice of dining out can be discussed from environmental, social, and economic perspectives. In the environmental dimension, the practice is discussed in relation to climate change, the depletion of nature resources, and the generation of food waste. The social issues 
at stake are animal well-being, fair trade, obesity, malnutrition, and unequal access. Economic issues relate to affordability and employment among others [25]. From the point of view of service providers, it has been pinpointed that some operational practices of restaurants result in low overall sustainability performances such as by using inefficient equipment that cost more energy and water, by using throw-away utensils, by buying and selling food products that are produced in an irresponsible way, or by failing to provide training and assistance to employees on perform practices in more sustainable ways [26]. In the meantime, consumers also contribute to the previously mentioned sustainability issues. On the one hand, consumers' food choices can influence the sustainability performance of the dining out practice. For example, a provenance of ingredients can affect the carbon footprint of the food. Exotic ingredients that need long distance transportation lead to more food miles and, therefore, increase the carbon footprint of the food [27]. Meanwhile, meals with more meat, vegetables grown in heated greenhouses, and non-seasonal ingredients tend to lead more environmental problems [28,29]. Moreover, the unhealthy food choice can lead to obesity and malnutrition [30]. On the other hand, consumers' food waste was defined as a major issue that hampers the sustainability performance of the dining out practice. Bloom [31] found out that $17 \%$ of restaurant food is uneaten by consumers and only $45 \%$ of these leftovers are taken home and saved for future consumption. Leftovers generated by consumers are associated with the reasons e.g., big portion size of the main dishes, too much side dishes, and unfavorable tastes [32,33]. Most often, consumers refuse to take the leftovers due to the reasons, e.g., the embarrassment that comes with asking doggy bags in public, concerns on food safety (e.g., foodborne illness), and preferences for the freshest food [34].

After the identification of the issues, sustainability quantification of the practices is the next step. Since "sustainability" is an ambiguous concept with complex social and natural interaction, direct measurement is essentially impossible [35]. Instead, a set of quantifiable indicators needs to be found as the "alternative measures" to reflect the sustainability level of the evaluation target [36]. The indicators can be distinguished as the science-based indicators and practice-based indicators. The science-based indicators are the ones widely used in the academic world that provides scientifically useful information, e.g., carbon footprint to measure the impacts on climate change. As a comparison, the practice-based indicators provide practically sensible information to broader audiences. For example, "food wasted during dining out (in kilo or euro)" is the practice-based indicator that conveys the message as highly interesting from a practitioner's point of view. Through the quantification, we could, for example, derive a sustainability score of the dining out practice (i.e., sustainability performance scores for practice A, as indicated in Figure 1), which can provide scientific/practical information to relevant stakeholders, such as consumers, catering industry, and policy makers. For the catering industry or policy makers, this score can be, for example, used for the purpose of benchmarking or regulation. For consumers, this score can be, for example, used to monitor their own progress in becoming more sustainable or comparing their performances with that of the general population or their social network [37]. In addition, the sustainability score could be combined with other useful information on e.g., improving health, saving money, etc. to make it more acceptable by the consumers.

\subsection{The Role of Mobile Apps as Interventions and Instruments for Co-Constructing Sustainability Transitions} in Food Practices

The role of mobile apps as interventions and instruments for co-constructing sustainability transitions in food practices is illustrated in Figure 1 (box III). This section is divided into two sections, where interventions and forms of co-construction will be first discussed in Section 2.3.1, and then the role of mobile apps in co-constructing sustainability transitions in food practices will be deliberated in Section 2.3.2. 


\subsubsection{Interventions and Forms of Co-Construction}

To actively facilitate the sustainability transition of practices, interventions need to be organized in such a way that consumers go along with and actively co-shape more sustainable variants of the food consumption practices. A special focus of our conceptual framework is on investigating the interacting dynamics between food practices and mobile apps as well as their combined roles in the sustainability transitions. This framework acknowledges the essential role that mobile apps play in bridging the traditionally isolated "practice/sociological" and "science/technical" paradigms for a food practice transition and tries to integrate them as one synthesized research topic for in-depth studies. Therefore, we deliberately separate mobile apps out of the general "technology" block to emphasize their importance.

The interventions and forms of co-construction, which can de-routinize the current performances of the practice, may target one or more of the existing elements (i.e., skills, objects, technology, and goals) of the practice while suggesting an alternative, more sustainable variant. In this scenario, we suggest two types of interventions. The first type of interventions have a link with information provision on sustainability. For instance, providing sustainability information at the consumption junctions e.g., using Traffic light labels on the menu to attract consumers to make more sustainable choices. The Traffic light label is the intervention that de-routinizes the "information flow" from the product and product provider to the consumer, which could, therefore, alter a consumer dining out experience and, ultimately, changes their food practice [15]. The second type of interventions are practical interventions that change the specific set-up or combination of elements belonging to the practices. One example is providing a limited variety of dish menus (changing the "object") to reduce food waste in the restaurants [34].

By looking into the dining out procedure for consumers, potential interventions can be identified to stimulate the transitions from the current practice of dining out toward the adapted (i.e., more sustainable) practice of dining out. Figure 2 listed the major dining out procedures where consumers need to adapt their behaviors and decision-making during the different phases in the enactment of the practice, i.e., picking a restaurant, using a transportation mode, picking a menu, and managing leftovers.

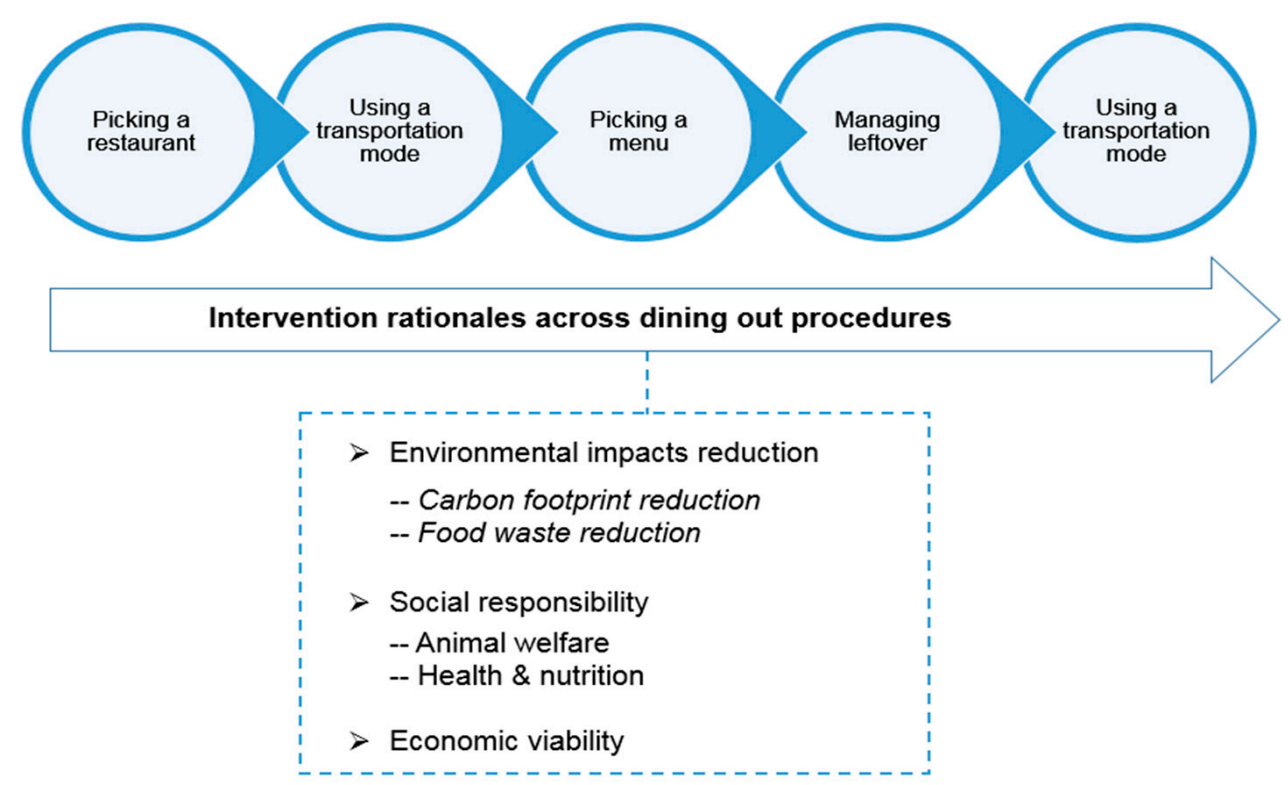

Figure 2. Rationales for co-constructing transitions for sustainable dining out practices. 
Based on the previously mentioned sustainable issues in the practice of dining out, the rationales for interventions and forms of co-construction can be categorized into three dimensions or aspects (see in Figure 2), which comply with the commonly used definition of sustainability that incorporates environmental, social, and economic perspectives [38]. The first rationale is to reduce environmental impacts of the dining out practice by reducing food waste and the carbon footprint [34]. The second rationale is to be socially responsible, so that future dining out practices incorporate issues like animal welfare, health, and nutrition $[25,26]$. The third rationale is to make the practice of dining out economically viable [39]. All these rationales can play a role at the different phases of the practice, which relates to different procedures and dynamics. By taking into account more than one rationale, the interventions and forms of co-constructing are expected to be more effective due to attractiveness to consumers.

Major interventions and forms of co-construction have been identified in previous studies (see Table 1). They have been proven to be useful to facilitate the transition from the current practice of dining out towards a more sustainable performance of the practice. To be able to specify the forms of co-construction relevant for the practice, we indicate which actors have the primary responsibility for making the interventions effective. This can be consumers, restaurants owners, or both e.g., a shared responsibility of restaurant owners and consumers. For all the different phases and their specific dynamics of change, we will shortly discuss this organization of responsibilities for sustainability transitions in the practice.

Table 1. Sustainable interventions for consumers in different dining out procedures.

\begin{tabular}{|c|c|c|c|c|}
\hline \multirow{2}{*}{$\begin{array}{c}\text { Phases and } \\
\text { Procedures in the } \\
\text { Dining Out Practice }\end{array}$} & \multirow{2}{*}{$\begin{array}{l}\text { Interventions and Forms } \\
\text { of Co-Construction for } \\
\text { Sustainable Practices }\end{array}$} & \multirow[t]{2}{*}{ References } & \multicolumn{2}{|c|}{ Primary Responsibility } \\
\hline & & & Restaurant & Consumers \\
\hline Restaurant Selection & $\begin{array}{ll}\text { - } & \text { Nearby restaurants } \\
\text { - } & \text { Good price quality restaurant } \\
\text { - } & \text { Restaurants with vegetarian options } \\
\text { - } & \text { Restaurants with green practices } \\
\text { - } & \text { Knowledgeable personal }\end{array}$ & $\begin{array}{c}{[30,40]} \\
{[30,40]} \\
{[25,30,41]} \\
{[25,30,41]} \\
{[25,30,41]} \\
{[25,30]}\end{array}$ & $\begin{array}{l}- \\
- \\
-\end{array}$ & $\begin{array}{l}+ \\
+ \\
+ \\
+\end{array}$ \\
\hline $\begin{array}{l}\text { Transportation mode } \\
\text { Selection and Use }\end{array}$ & $\begin{array}{ll}\text { - } & \text { Walk } \\
\text { - } & \text { Bike } \\
\text { - } & \text { Car-Pooling } \\
\text { - } & \text { Public transport }\end{array}$ & $\begin{array}{l}{[40,42,43]} \\
{[40,42-44]} \\
{[40,42,43]} \\
{[40,42-44]}\end{array}$ & $\begin{array}{l}- \\
- \\
- \\
+\end{array}$ & $\begin{array}{l}+ \\
+ \\
+ \\
+\end{array}$ \\
\hline Menu Selection & $\begin{array}{ll}\text { - } & \text { Pre-order food } \\
\text { - } & \text { Menu variety reduction } \\
\text { - } & \text { Portion size } \\
\text { - } & \text { Side dishes } \\
\text { - } & \text { Whole animal parts } \\
\text { - } & \text { Seal food } \\
\text { - } & \text { Less meat food } \\
\text { - } & \text { Animal welfare } \\
\text { - } & \text { New protein substitutes } \\
\text { - } & \text { Nutritional information } \\
\text { - } & \text { Allergy indication }\end{array}$ & $\begin{array}{c}{[34,45,46]} \\
{[25,34,45]} \\
{[25,33,34,45,47]} \\
{[25,34,45]} \\
{[25,45]} \\
{[25,34]} \\
{[25,34]} \\
{[25,30,41]} \\
{[25,30,41]} \\
{[25,30,41]} \\
{[25,40,48]} \\
{[25,40,48]}\end{array}$ & $\begin{array}{l}+ \\
+ \\
+ \\
+ \\
+ \\
+ \\
+ \\
+ \\
+ \\
+ \\
+ \\
+\end{array}$ & $\begin{array}{l}+/- \\
+/- \\
+/- \\
- \\
- \\
+/- \\
+/- \\
+/- \\
+/- \\
- \\
+/- \\
+/-\end{array}$ \\
\hline Leftover management & $\begin{array}{ll}\text { - } & \text { Doggy bag } \\
\text { - } & \text { Recipe to make innovation } \\
\text { - } & \text { Food quality info on leftover }\end{array}$ & $\begin{array}{l}{[33,49,50]} \\
{[34,45,48]} \\
{[34,45,48]}\end{array}$ & $\begin{array}{l}+ \\
+ \\
+\end{array}$ & $\begin{array}{l}+/- \\
- \\
-\end{array}$ \\
\hline
\end{tabular}


Starting with the first procedure or phase of dining out i.e., picking a restaurant, interventions, and forms of co-construction can take different forms. To stimulate consumers to pick restaurants for more sustainable forms of dining out promoting the restaurants that are nearby, restaurants with more and better vegetarian options, restaurants with green procurement and cooking practices, restaurants with good green quality for price ratio etc. may be helpful. In this procedure, consumers are primarily responsible because, in the end, they are the actors picking a specific restaurant from a wide range of available options.

The second phase and procedure of dining out refers to the use of a specific transportation mode to get to the restaurant and back home. The available transportation modes, the model shift options, the connection with the dining out locale (parking, distance to station), the indication of the travel time needed, the associated cost, and associated carbon footprint are all relevant ingredients in the process of consumers getting to and from the restaurant in more sustainable ways. Although consumers still carry the primary responsibility for actually using a transportation mode, we would argue that this responsibility is shared by restaurants in terms of making their site of consumption more accessible for sustainable transportation modes and for communicating about this with future customers.

Many interventions and forms of co-construction are relevant in the third phase of performing the practices with respect to the rules and procedures that apply in this phase of picking a menu. Dining out will be made more sustainable when consumers show preferences for greener food choices both at the level of menu, dish, and ingredients [16]. Reducing food waste can be realized by possibilities to pre-order food before coming to the restaurant, providing less menu varieties, indicating the portion size, and allowing customers to order smaller portion, freedom to choose the side dishes, and dishes made by using the whole animal parts. To reduce the carbon footprint, the menu could e.g., suggest dishes with seasonal products, less meat, animal friendly produced meat products, or new protein substitutes (e.g., plant-based, tissue cultivated). With regard to the health and nutrition aspects, providing nutritional information and advices, and indicating the allergy ingredients that can be considered. We would argue that restaurants carry the primary responsibility for all the previously mentioned interventions because, as the supplier, they take the leading role in making the interventions and forms of co-construction available and accessible both 'in situ' and on the web. Depending on the availability and accessibility of the interventions, consumers can either take the shared responsibility with restaurants or take a secondary role next to restaurants. For example, if the restaurant is still in the stage of not offering too many choices on e.g., local food, seasonal food, then it is more of the responsibility of the restaurant than to the consumers. However, if the restaurant is already offering quite a lot of varieties, then it depends on the familiarities to consumers. For the common things e.g., local food, portion size, then it is the shared responsibility of consumers with restaurants because consumers are the ones who need to make the final decisions. Nevertheless, for the new concepts e.g., new protein substitutes, it is more the responsibility of the restaurants because consumers still need to be guided on it.

The last but not least phase of the practice refers to managing leftover. Interventions and forms of co-construction in this phase that have been suggested so far are e.g., advocating the usage of doggy bags, providing innovative leftover recipes, and giving guidance with respect to managing the food quality of leftovers. In this phase and for this procedure, the restaurant is still in the lead when developing different sustainable options. Given the fact that, in some countries, doggy bags and their particular uses are a standard provision by restaurants. Consumers have to take an active role as co-constructors by actually using them in a routinized way.

\subsubsection{The Role of Mobile Apps in Co-Constructing Sustainability Transitions in Food Practices}

It has been witnessed that mobile apps have become an indispensable part of consumer food practices and have been actively carrying the role in reshaping routine behaviors of consumers [12,37]. For example, consumers in China use their E-wallets for payment instead of traditional cash or card payments. For convenience and effective information obtainment, it has become more popular among consumers to use mobile apps for all kinds of food practices such as dining out, shopping 
for food, and home cooking [48]. Research has shown that it is difficult for consumers to make sustainable food choices in the restaurants when they are not well-informed with the consequences of their choices [51,52]. Nevertheless, providing too much or too technical information can overwhelm consumers, especially when the purpose of dining out is to relax and seek enjoyment [25]. With the assistance of IT (e.g., mobile apps), the previously mentioned interventions can be naturally plugged into each procedure of the dining out practice, and, therefore, makes the transitions more smooth. How to best incorporate the previously mentioned potential interventions in the context of mobile apps is critical for the success of the transitions.

With the development of IT, more appealing types of interventions can become available to shape consumers' daily food practices. Figure 3 illustrates some popular IT technologies, which can be applied in the mobile apps as instruments to support and organize interventions and forms co-construction to facilitate the sustainable transitions in the practice of dining out. Virtual reality in mobile apps, for example, can provide vivid images to consumers to replace the traditional textual-based explanations. In this way, consumers can have access to the sustainability in a quick and easy-to-understand way [15]. Meanwhile, QR code technologies allows digital menu possibilities in the mobile apps, so that consumers can easily get the information e.g., provenance of ingredients, nutritional values of the menu, etc.
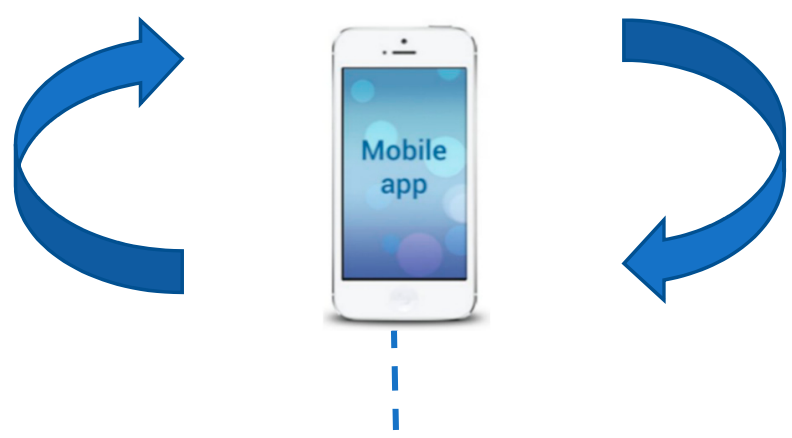

\begin{tabular}{ccc}
\hline IT Technologies & Application Examples & References \\
\hline Visualization & $\begin{array}{c}\text { Virtual reality } \\
\text { e.g., visualizing the effects of the environmental } \\
\text { consequences }\end{array}$ & {$[15,53]$} \\
\hline Digitalization & $\begin{array}{c}Q R \text { code } \\
\text { e.g., digitization of menu, traceability of ingredients } \\
\text { Internet of Things }\end{array}$ \\
& $\begin{array}{c}\text { e.g., link the tableware with the mobile apps to monitor } \\
\text { the speed of eating } \\
\text { Gamification }\end{array}$ \\
& $\begin{array}{c}\text { e.g., monitoring transition progress with self or others, } \\
\text { making social connections through social media }\end{array}$ \\
\hline Artificial intelligence & $\begin{array}{c}\text { Personalization } \\
\text { e.g., provide personal recommendations based on the } \\
\text { health status and personal preference }\end{array}$ \\
\hline
\end{tabular}

Figure 3. IT technologies supporting sustainability transitions in dining out practices.

The development of Internet of Things technology makes automatic intelligent interventions possible. For example, the mobile apps can be linked with digital tableware. When the speed of eating is too fast, the mobile will vibrate to alert consumers to slow down food intake [56]. Moreover, gamification features add the fun elements into the mobile apps. Consumers could monitor their own transition progress or compare with others in a fun way. Meanwhile, they could also make social connections through social media (connected via the mobile apps). In addition, with the unlimited data storing and analyzing capability, artificial intelligence can enable the continuous recording and 
analysis of consumer historical behaving pattern and personal status (e.g., health status) to provide the basis for making up more effective intervening strategies that can be applied in the mobile apps.

Despite all the fascinating benefits brought by these advanced IT technologies, cautions should be made with the shadow side of the technologies. For instance, data privacy was identified as a major concern by citizen-consumer in the study of Davies [12], where consumers were involved in co-assessing the role of technology in shaping sustainable eating futures. Citizen-consumers raised up the concerns over issues e.g., who would collect the detailed and widespread data from them? Who has the access to those personalized data? And what will their data be used for?

\section{Methodological Aspects: Focus Groups with Chinese and Dutch Young Consumers}

As a qualitative method, focus group discussions have the advantage of creating a flexible environment that allows participants to express their feelings and generate innovative ideas on a topic [57]. Given the fact that the research topic in this paper is newly emerging and the character of the research is exploratory, we, therefore, deliberately selected focus group discussions as the methodology to further validate our conceptual framework. Since we do not want to present the framework to limit the discussions, but rather to propose a series of open ended questions and encourage participants to identify the important issues and set up priorities for their discussions, focus group discussions could allow group dynamics that can empower participants to better bring forward their own perspectives and develop ideas collectively [58]. Although the results from focus groups are not intended to be generalizable to larger segments of the population e.g., dining out participants, they could help us gain the deep insights from the consumers on the research topic.

\subsection{Participants}

We organized two sessions of focus group discussions including one for Chinese participants and one for Dutch participants. The popularity of using mobile apps in the dining out practice is much higher among Chinese consumers when compared to Dutch consumers. This makes it more interesting to gather opinions and experiences from citizen-consumers from both countries. For each country, we recruited 10 participants. All participants are from the millennials generation, which is categorized as an extensive user of Internet and mobile technologies. For practical reasons, the participants were recruited from Wageningen University. They are either students or staff members of the university and have an affinity with mobile apps. Although the Chinese participants are recruited from the Netherlands, we deliberately selected the participants who are familiar with the digitalized lifestyle in China. For each session of the focus group discussions, there were 10 participants including five female and five male participants for the gender balance. A small financial reimbursement was provided to the participants for their time and efforts.

\subsection{Instrumentation and Procedure}

Two focus group discussions were conducted in the year 2018. A week before the focus group discussions, the participants received an information package (see Supplementary Materials) introducing the case study of dining out and mentioning the reasons for being invited to the focus group discussions. The participants were asked to familiarize themselves with the information package before the discussion. The discussion lasted approximately $60 \mathrm{~min}$ per session, which started with a 10-min introductory presentation by the first author on the background of the research, basic knowledge on practice theory, on the case study of dining out, and as semi-structured guidelines on the themes and questions to be discussed. The themes and questions can be found in Table A1 (see Appendix A). At the end of the introductory presentation, participants were asked to imagine themselves being about to start the dining out procedure and making a choice on a type of the restaurant they would like to explore among fast food outlets, cafeteria, normal restaurants, and luxury restaurants.

After the introduction, the 10 participants were divided into three groups and they were provided with a handout showing organizing themes and questions for the focus group. They started with 
writing down their own opinions on the themes and questions for the first $5 \mathrm{~min}$, which was followed by a group discussion for approximately $25 \mathrm{~min}$ with one at the end summarizing their ideas on a poster paper. In the last $20 \mathrm{~min}$, each group had a representative to present their group views as well as discuss their findings with other groups. The final presentations made by groups was recorded and transcribed verbatim.

\section{Empirical Results}

The results presented in this section originate from the consensus of the focus group discussions, unless it is indicated otherwise. When being asked to set the reference context among all the possible choices (i.e., fast food outlets, cafeteria, normal restaurant, and luxury restaurant) for the discussions, normal restaurants were selected by all the groups. In general, all participants advocate the use of mobile apps in assisting them to become more sustainable when performing food practices. For analysing the outcomes of the discussions, we summarize the findings under three main themes i.e., suitability of mobile apps in the context of dining out (see Section 4.1), relevant sustainability issues in the context of dining out (see Section 4.2), and attributes of the food app in the context of dining out (see Section 4.3).

\subsection{Suitability of Mobile Apps in the Context of Dining Out}

Participants from both Chinese and Dutch sessions indicated that they adapted their normal behaviors due to the ever more frequent use of mobile apps. For instance, they tend to rely on the suggestions and reviews made available via the apps when making their decisions.

One of the participants indicated the nature of the behavioral changes and the advantages of the mobile app as follows.

"By using apps, we could reduce asymmetric information. Before we go to the restaurant, we could get to know the restaurant, useful information on the menus (e.g., varieties, cost), feedback from the people who have been eating there. This saved us searching time in the restaurant, we could make pre-decisions" (Chinese participant).

Meanwhile, one Dutch participant also argues that mobile apps can be helpful with making her diet decisions.

"I have a quite complicated diet. Sometimes I need to check with the app if I can have a specific food, so yes, that changes my behavior."

However, participants from both countries also expressed some concerns regarding to the use of the mobile app in picking a restaurant. Some of them think that the pitfalls of using the mobile apps are the longer overall period of time used for picking a restaurant, and, in the end, being less creative with the restaurant selection.

"Because of the app, we spent more time on the selection of the restaurant. Without the app, we would just go to the nearby restaurant, but now we may go somewhere that needs half an hour driving. So the overall practice takes us more time." (Chinese participant).

"Mobile apps e.g., Google travel kind of lead you in the direction because you kind of base your idea on the review. You become less creative because you are not just going to a restaurant and see what it brings you, you read reviews beforehand, and make your decisions" (Dutch participant).

Others participants think that using mobile apps could lead to overconsumption and food waste.

"Sometimes the promotion deal provided in the app is only available for four people. Although we are only three, we will still go for the deal for the good price, but we end up wasting food" (Chinese participant). 
Despite the previously mentioned pitfalls of mobile apps, participants are still in favor of using mobile apps to facilitate sustainability transitions in their daily food practices. In the context of dining out, Chinese participants, however, showed more enthusiasm than the Dutch participants. For Chinese participants, mobile apps have already become an indispensable part of their dining out practice. They mentioned all kinds of apps they are using for a dining out purpose. They use apps e.g., Dianping (for restaurant reviews), Meituan-Dianping (for group buying) in the procedure of restaurant selection. Meanwhile, apps e.g., OFO (for bicycle sharing), Didi Chuxing (for ride sharing), Werun (for steps counting) are used for organizing their transportation to the restaurant. In the menu selection procedure, they use Wechat, Alipay for accessing the QR code of the menu. The Chinese participants, therefore, value mobile apps to be part of their dining out procedure and anticipate that future apps can be helpful for improving their dining out practice.

"We think that the concept of this future food app is nice. It can help our lifestyle become more healthy and digitalized" (Chinese participant).

"If the apps can, all the time, advertise healthy diets and explain the advantages of the healthy diet, maybe we can eventually change our diet for the sake of health" (Chinese participant).

Nevertheless, the story turns out to be a bit different for the Dutch participants. Although they do think that mobile apps can facilitate sustainability transitions in their everyday behaviors, they tend to value the use of apps less in the particular context of dining out. Although they also use apps e.g., TripAdvisor, Google Map for searching restaurants, they do not see direct links between sustainability and the food practice of dining out. Nevertheless, they did express the preference to have such an app for other daily food practices e.g., grocery shopping, where sustainability is more of an issue to them.

\subsection{Relevant Sustainable Issues in the Context of Dining Out}

Different sustainable issues are pinpointed as relevant by the Chinese and Dutch groups. In general, Dutch participants do not consider sustainability issues important in the dining out context because they treat it as a special and relaxing event.

"Dining out is so special, I don't want to think about sustainability in it, I care about the sustainability in my other daily activities. For example, I only eat meat twice a week, then I don't think it's a problem to eat meat when dining out" (Dutch participant).

Nevertheless, some Dutch participants did point out for certain groups of people, e.g., high-income business class, dining out can be a customary practice and apps in those cases can be of value when making the linkage with sustainability issues.

"We think that the concept of developing food apps for improving the sustainability of dining out is nice, but you need to have the right target group. Like if you only eat out once a month, then it is not interesting or less interesting for you to see if it is environmentally-friendly or sustainable, you just go there for fun. But if you are a person in Amsterdam like a lawyer, I don't know, or high level business person who eat out all the time, then maybe it's good to have them think about going to more sustainable restaurants" (Dutch participant).

Meanwhile, some Dutch participants also mentioned their preference on good price/quality food, local food, and animal welfare-friendly food products including vegan food when dining out.

"But we do like local food. If a restaurant offers local food, then it's good for eaters" (Dutch participant).

"For sustainability, we focus more on the economic side, we are all students, we check the price of the restaurant before we go there, price quality is quite important for us. For the environmental issues, for us it's important to know the footprint of the menu, the weight of the menu, originality of the food." (Dutch participant). 
Moreover, they tend to shift the responsibility for sustainability issues to the restaurants. For example, they prefer to pick the more sustainable restaurants and not to overload themselves with sustainable menu selection before or after entering the restaurant.

"I think that the menu selection is not a good idea, but restaurant selection can be helpful. So that I chose the sustainable restaurant, then what I do there, I assume to be sustainable" (Dutch participant).

Unlike the Dutch participants, Chinese participants do see the importance of sustainability issues in the dining out practice because dining out is more of a regular practice for them. Nevertheless, for both Dutch and Chinese participants, their interests on the economic dimension of sustainability coincide.

"Another important issue is saving cost, so Meituan-Dianping (an App for group buying) can recommend you good price/quality or cheap restaurants and good promotion sales" (Chinese participant).

"Environmental sustainability and social sustainability should always be considered together with economic sustainability. Otherwise, it's not going to work out" (Chinese participant).

Next to the economic dimension, Chinese participants pay particular attention to social issues e.g., food safety and health.

"We think that food safety is very important. We think that healthy issues are more important. We care less about the environment." (Chinese participant).

They, therefore, are interested to be informed on food traceability as well as nutritional values of the meal to achieve a healthy diet. In addition, food waste is also stressed as an important issue that they would like to tackle with an app. Information on the portion size is appreciated.

"We want the app to provide detailed information on the food (e.g., ingredients, nutritional value, calories, more precise portion size) so that we can get a balanced diet and do not waste food. In addition, we would like to have the function of food traceability" (Chinese participant).

"Apps maybe can provide how much did we waste, so that if we waste food all the time, we will feel ashamed and will try to improve. In general, we want the app to help us find the balance of having enough food and not waste food" (Chinese participant).

Meanwhile, due to the Chinese culture of showing generosity when treating guests, the participants pinpoint the need of guidance on keeping the balance of no/less waste and being generous. Even in the worst scenario that the food waste cannot be avoided, they would like to know the waste management strategy of the restaurants.

"As Chinese, when we treat friends, we want to order more than is needed to show our generosity. This often leads to food waste. The app can provide some guidance to cope with this culture issue and help us reduce food waste. In addition, we would like to know the food waste management of the restaurant. If they go for donating to the poor person, or use them for bio energy, then we feel better than doing nothing and purely waste all the resources" (Chinese participants).

In addition, environmental issues were mentioned by a few participants as being rooted in other concerns than the sustainability of food e.g., related to health concerns that are connected with specific environmental issues.

"Because of the severe smog in Beijing, we also start to pay attention to the environmentally-friendly behavior" (Chinese participant). 


\subsection{Attributes of the Future Food App in the Context of Dining Out}

Some common features for the future food app were raised by both Dutch and Chinese participants. First, the app should be rewarding using monetary benefits (e.g., discount, vouchers) and social benefits (e.g., feeling superior among friends). Second, information provided by the app should be reliable and trustworthy. Third, the app itself should be simple to use and functional and should not contain too many advertisements and pop up messages.

"To make us use the apps continuously, it needs to be handy to use and help us save cost, e.g., constantly provide promotion sales. Not too many advertisement and unreliable information" (Chinese participant).

"We think the apps should be rewarding, simple, and functional, and also the social sharing is important because then you can sort of brag to your friend that I'm eating environmentally-friendly and being good to the world" (Dutch participant).

Participants from both countries opt for one integrated mobile app, which includes all restaurants instead of having different apps for different restaurants. In the meantime, they prefer to use an existing well-known app that they are already familiar with, and then integrate the sustainability concepts into the app.

"We want to have the apps provide info on different types of restaurants, not on one individual restaurant. Otherwise, we end up with too many apps and we might delete them later on" (Chinese participant).

"We think that it should be collaborating with the existing apps (e.g., Meituan-Dianping). Otherwise, it's too much repetition with other apps" (Chinese participant).

"We already use apps like TripAdvisor to review/compare restaurants and also find the nearby restaurants so that it will be easier if it iss integrated with the apps that are already being used, so you do not need to switch every time between apps. For example, in TripAdvisor, you say I want to go to this restaurant because of the good review, then you go to the other app that says this restaurant is not sustainable. Therefore, you have to switch around. That is generally annoying and you do not want to waste time on that. Therefore, we think it is better to integrate it" (Dutch participant).

Participants from both countries raised the importance of incorporating personalization features into the development of the future food app. For example, Dutch participants mentioned that the sustainability rating of the restaurants should be calculated based on the individual preference of the app users due to the fact that people tend to value different dimensions of sustainability.

"Give scores to the restaurant. You have an overall sustainable score for different restaurants. But also provide subgroups of sustainability scores for the restaurants (e.g., animal welfare scores, economic scores for people have special interests in certain aspects of sustainability). You can choose what is more important to you, so the rating is always generated user specific" (Dutch participant).

"If you develop the apps, we can indicate the kind of food and the price we want to pay. Then the app can provide a list of the most sustainable restaurants" (Dutch participant).

Likewise, Chinese participants also indicated the need of personalized themes. For example, they could set their priorities in the app, so that the app can provide recommendations or useful information, according to their preference.

"We would like to have an intelligent app that can provide more flexible recommendations based on our requirement e.g., today I want to eat more healthy, or today I want to just relax and eat not so healthy but tasty food, or today I want to save money" (Chinese participant). 
On the other hand, Chinese participants also anticipate that the dining out app can be connected with other apps e.g., the fitness app, so that more personalized assistance can be made available.

"The dining out app can be linked with the fitness app. For example, if I'm trying to keeping fit, the dining out app can provide what I can eat for my target" (Chinese participant).

Similar thoughts were discussed in the Dutch group. Dutch participants, however, were shown to be more cautious about the app recording all their daily food practices. They neither want to spend too much time with the app nor expose their personal data to it.

"I do not want all my food practices to be recorded in the app. I can make choices myself, but if an app registers everything, then I also need to give input a lot. I do not want to be on my phone all the time" (Dutch participants).

\section{Discussion}

There have been numerous studies that illustrate the importance of applying social practice theory to study the transitions in food practices [2,9,18]. However, Davies [12] was the first study that address the importance of technology and ICT when applying the social practice approach to study the co-creation of sustainable eating futures. The innovativeness of this research is to explore how technology and ICT (e.g., mobile apps) can be served as effective instruments in linking the social practice approach with food sustainability and facilitating the sustainable food transitions.

Through the focus group discussions, we found that there are prominent differences between the Chinese and the Dutch participants regarding both the prevalence of using mobile apps for the dining out practice and the opinion on the role of mobile apps in improving relevant sustainability issues associated with the dining out practice. Compared to the Dutch participants, the Chinese participants are more acquainted with mobile apps in general, especially when it comes to using apps specifically for the dining out practice. Chinese participants valued the role of mobile apps in guiding them towards more sustainable behavior in all procedures of the dining out practice. They even have the expectation that the apps are the solutions to all their sustainable issues. Economic viability, food safety, health, and food waste are the most concerning issues for them in terms of sustainability. They were shown to be active in the co-constructing future sustainable dining out practices by identifying the essential elements in each procedure of dining out where mobile apps can be used as effective interventions and instruments. On the contrary, for the Dutch participants, the picture of how mobile apps can be relevant and useful for them to have a more sustainable dining out practice is still rather abstract and fuzzy. Although Dutch participants care about sustainability in relation to food, they do not think of themselves as a relevant target group for an app targeting dining out as a particular food practice. The different insights from the Chinese and Dutch participants show that there is no universal format of the future food practice related mobile apps. The designing of the apps should be context (e.g., practices, culture) specific.

Despite the differences between Chinese and Dutch participants, insights into how the future mobile app for the dining out practice are obtained. Both Chinese and Dutch participants prefer one integrated app, which is built upon an existing and well-known app associated with the dining out practice. The app should be simple to use, functional, and offer the flexibility in terms of allowing users to set their preferences. Meanwhile, the app should be rewarding regarding both monetary benefits (e.g., discount, vouchers) and social benefits (e.g., feeling superior among friends). Last but not least, information provided by the app should be reliable and trustworthy.

To realize a trustworthy app, future research studies on how people perceive the information as reliable are needed. We suggest the future food apps should be constructed with both science-based knowledge and practice-based knowledge. For example, scientists and experts are expected for selecting the relevant and feasible indicators for quantifying the sustainability issues within different food practices. Meanwhile, practitioners should also be involved to co-develop the practice-based 
indicators and, at a later stage, co-design the interventions that are effective for shaping the sustainable food behaviors.

In this study, we only studied the dining out practice. Nevertheless, other food practices e.g., shopping for food, cooking, and food gardening should be looked into in-depth as well, by following the same procedures conducted for the practice of dining out. By identifying and analysing all the components of the practice, sufficient guidance can be provided to consumers on how the expected behavior changes can be operationalized and implemented in their food practices. In this study, we only focused on the young consumers due to their affinity with mobile apps. Future research is suggested to take more segments of consumers into account. In addition, more attention should be paid into the future research on interactions between food practices as well as the linkages with the non-food related practices (e.g., practice of using mobile apps).

\section{Conclusions and Implications}

In this research, the feasibility of using mobile apps to facilitate the consumption-end sustainable transitions of food practices and the role of consumers in it were investigated. A conceptual framework, which is based on practice theory, was developed to serve as a guideline for the investigation. The framework pinpointed that it is essential to co-construct mobile apps with consumers by understanding the food practices, identifying relevant sustainability issues in different food practices, and exploring how mobile apps can be best of use in changing their current food practices toward more sustainable food practices.

Through the case study on the practice of dining out, we found that a single dining out app is preferred, which means integrating the dimension of sustainability with a dominating app already in use for the purpose of dining out. The findings from this study can also be generalized for other food practices. The concept developed in this paper could be integrated in a currently used food app in other practices (cooking, online shopping), while keeping the door open for the option of bringing all the food practice related apps in a common platform at a later stage. Nevertheless, there is no universal format of the mobile apps for food practices. The format might vary among different contexts (e.g., different culture, different practice). To construct the future food apps, we suggest to incorporate both science-based knowledge and practice-based knowledge. The information provided by the apps should be based on independent and scientific sources and be controlled by the group of communities (e.g., scientist, experts, practitioners) to avoid biased information. With the ongoing development of future food-related apps, our research set the first building blocks for providing guidelines on how to enhance the role of mobile apps in sustainable transitions of food practices.

Supplementary Materials: The following are available online at http://www.mdpi.com/2071-1050/11/5/1275/s1.

Author Contributions: Conceptualization, W.M., G.S., and A.O.L.; Methodology, W.M., G.S.; Investigation, W.M.; Writing-Original Draft Preparation, W.M., G.S., and A.O.L.; Writing-Review \& Editing, W.M., G.S.

Funding: This research was funded by Wageningen UR strategic program 'Resource Use Efficiency', 2017-2019, project number 2100949300.

Acknowledgments: The authors would like express their gratitude towards Bedir Tekinerdogan, Gert Jan Hofstede, Willie van den Broek, Koen Boone, Xuezhen Guo, Giulia Salvini, Jan Vogels, Roel Helmes, Jos van den Puttelaar, Liesbeth Temme, Gerdine Kaptijn, and Lisanne van Geffen and Peter Oosterveer for their contribution with the development of conceptual framework and two anonymous reviewers for their valuable comments and suggestions to improve the quality of this paper. This research is part of the Wageningen UR strategic program 'Resource Use Efficiency', 2017-2019.

Conflicts of Interest: The authors declare no conflict of interest. 


\section{Appendix A}

Table A1. Semi-structured guidelines on the themes and questions for focus group discussion.

\section{Mobile Apps}

- Do any mobile apps you use currently have a link for dining out? What kind of function do those mobile apps serve? (e.g., transportation mode selection, menu selection, etc.)

- What makes you like or dislike the mobile apps you are using?

- Did you experience any behavioral change due to using mobile apps? Explain.

\section{Sustainability Issues in the Context of Dining Out}

- In the mobile apps you are using currently, are there any apps with a role in promoting sustainability?

- Which sustainability (i.e., social, economic, and environmental) issues are important for you in the context of dining out?

- Would you like to get information about the importance of sustainability and how you can increase your sustainability? What would you like to get?

- In the context of dining out, did you ever get involved in making more sustainable choices? How did you get involved? Did you like or dislike the experience? What makes you like or dislike the experience?

\section{Dining Out Food Apps for Improving Sustainability}

- What do you think of the concept of using mobile apps to stimulate consumers to make more sustainable choices in the context of dining out in a restaurant?

- What would you like the mobile apps to look like? What kind of information would you like to get from the apps? Which features should it have (e.g., competition with self/others, social media)? What could make you feel interested in using such an app?

- Would you like apps provided by a specific restaurant or apps that provide info on different types of restaurants?

- What would make you use it continuously? What would make you stop using it?

\section{References}

1. Blok, V.; Long, T.B.; Gaziulusoy, A.I.; Ciliz, N.; Lozano, R.; Huisingh, D.; Csutora, M.; Boks, C. From best practices to bridges for a more sustainable future: Advances and challenges in the transition to global sustainable production and consumption: Introduction to the ERSCP stream of the Special volume. J. Clean. Prod. 2015, 108, 19-30. [CrossRef]

2. Spaargaren, G.; Oosterveer, P.J.M.; Loeber, A.M.C. Food Practices in Transition-Changing Food Consumption, Retail and Production in the Age of Reflexive Modernity; Routledge: New York, NY, USA; London, UK, 2012.

3. Verain, M.C.D.; Bartels, J.; Dagevos, H.; Sijtsema, S.J.; Onwezen, M.C.; Antonides, G. Segments of sustainable food consumers: A literature review. Int. J. Consum. Stud. 2012, 36, 123-132. [CrossRef]

4. Grunert, K.G. Sustainability in the Food Sector: A Consumer Behaviour Perspective. J. Food Syst. Dyn. 2011, 2, 1-12.

5. Devaney, L.; Davies, A.R. Disrupting household food consumption through experimental HomeLabs: Outcomes, connections, contexts. J. Consum. Cult. 2016, 17, 823-844. [CrossRef]

6. Spaargaren, G. Sustainable Consumption: A Theoretical and Environmental Policy Perspective. Soc. Nat. Resour. 2003, 16, 687-701. [CrossRef]

7. Southerton, D. Habits, routines and temporalities of consumption: From individual behaviours to the reproduction of everyday practices. Time Soc. 2012, 22, 335-355. [CrossRef]

8. Giddens, A. Modernity and Self-Identity; Polity Press: Cambridge, UK, 1991.

9. Schatzki, T.R. The Site of the Social a Philosophical Account of the Constitution of Social Life and Change; Penn State University Press: University Park, PA, USA, 2002. 
10. Spaargaren, G. Theories of practices: Agency, technology, and culture: Exploring the relevance of practice theories for the governance of sustainable consumption practices in the new world-order. Glob. Environ. Chang. 2011, 21, 813-822. [CrossRef]

11. Hinrichs, C.C. Transitions to sustainability: A change in thinking about food systems change? Agric. Hum. Values 2014, 31, 143-155. [CrossRef]

12. Davies, A.R. Co-creating sustainable eating futures: Technology, ICT and citizen-consumer ambivalence. Futures 2014, 62, 181-193. [CrossRef]

13. Huber, M.Z.; Hilty, L.M. Gamification and Sustainable Consumption: Overcoming the Limitations of Persuasive Technologies; Springer International Publishing: Cham, Switzerland, 2015; pp. 367-385.

14. Papworth, S.K.; Nghiem, T.P.L.; Chimalakonda, D.; Posa, M.R.C.; Wijedasa, L.S.; Bickford, D.; Carrasco, L.R. Quantifying the role of online news in linking conservation research to Facebook and Twitter. Conserv. Biol. 2015, 29, 825-833. [CrossRef] [PubMed]

15. Dunford, E.; Trevena, H.; Goodsell, C.; Ng, K.H.; Webster, J.; Millis, A.; Goldstein, S.; Hugueniot, O.; Neal, B. FoodSwitch: A Mobile Phone App to Enable Consumers to Make Healthier Food Choices and Crowdsourcing of National Food Composition Data. JMIR Mhealth Uhealth 2014, 2, e37. [CrossRef] [PubMed]

16. De Boer, J.; Aiking, H. Strategies towards healthy and sustainable protein consumption: A transition framework at the levels of diets, dishes, and dish ingredients. Food Qual. Prefer. 2018, 73, 171-181. [CrossRef]

17. Warde, A. Changing Tastes? The Evolution of Dining Out in England. Gastron. J. Crit. Food Stud. 2018, 18, 1-12. [CrossRef]

18. Warde, A.; Cheng, S.-L.; Olsen, W.; Southerton, D. Changes in the Practice of Eating: A Comparative Analysis of Time-Use. Acta Sociol. 2007, 50, 363-385. [CrossRef]

19. Van de Vijvere, S.; Lachat, C.; Kolsteren, P.; Van Oyen, H. Eating out of home in Belgium: Current situation and policy implications. Br. J. Nutr. 2009, 102, 921-928. [CrossRef] [PubMed]

20. Rezende, D.C.; Silva, M.A.R. Eating-out and experiential consumption: A typology of experience providers. Br. Food J. 2014, 116, 91-103. [CrossRef]

21. Warde, A.; Martens, L. Eating Out: Social Differentiation, Consumption and Pleasure; Cambridge University Press: Cambridge, UK, 2000.

22. Edwards, J.S.A. The foodservice industry: Eating out is more than just a meal. Food Qual. Prefer. 2013, 27, 223-229. [CrossRef]

23. Hanefors, M.; Mossberg, L. Searching for the Extraordinary Meal Experience. J. Bus. Manag. 2003, 9, $249-270$.

24. Bourdieu, P. Sport and social class. Int. Soc. Sci. Inf. 1978, 17, 819-840. [CrossRef]

25. Filimonau, V.; Lemmer, C.; Marshall, D.; Bejjani, G. 'Nudging' as an architect of more responsible consumer choice in food service provision: The role of restaurant menu design. J. Clean. Prod. 2017, 144, 161-170. [CrossRef]

26. DiPietro, R.B.; Cao, Y.; Partlow, C. Green practices in upscale foodservice operations: Customer perceptions and purchase intentions. Int. J. Contemp. Hosp. Manag. 2013, 25, 779-796. [CrossRef]

27. Garnett, T. Where are the best opportunities for reducing greenhouse gas emissions in the food system (including the food chain)? Food Policy 2011, 36, S23-S32. [CrossRef]

28. Mogensen, L.; Hermansen, J.E.; Halberg, N.; Dalgaard, R.; Vis, J.C.; Smith, B.G. Life cycle assessment across the food supply chain. In Sustainability in the Food Industry; Baldwin, J.C., Ed.; Wiley-Blackwell: Hoboken, NJ, USA, 2009; pp. 115-144.

29. Cohen, M.A.; Vandenbergh, M.P. The potential role of carbon labeling in a green economy. Energy Econ. 2012, 34, S53-S63. [CrossRef]

30. Baldwin, C.; Wilberforce, N.; Kapur, A. Restaurant and food service life cycle assessment and development of a sustainability standard. Int. J. Life Cycle Assess. 2011, 16, 40-49. [CrossRef]

31. Bloom, J. American Wasteland: How America Throws Away Nearly Half of Its Food (and What We Can Do about It); Da Capo Press: Cambridge, MA, USA, 2010.

32. Freedman, M.R.; Brochado, C. Reducing Portion Size Reduces Food Intake and Plate Waste. Obesity 2010, 18, 1864-1866. [CrossRef] [PubMed]

33. Hamerman, E.J.; Rudell, F.; Martins, C.M. Factors that predict taking restaurant leftovers: Strategies for reducing food waste. J. Consum. Behav. 2018, 17, 94-104. [CrossRef]

34. Neff, R.A.; Spiker, M.L.; Truant, P.L. Wasted Food: U.S. Consumers' Reported Awareness, Attitudes, and Behaviors. PLOS ONE 2015, 10, e0127881. 
35. Olsson, P.; Galaz, V.; Boonstra, W.J. Sustainability transformations: A resilience perspective. Ecol. Soc. 2014, 19, 1. [CrossRef]

36. Mitchell, G.; May, A.; McDonald, A. PICABUE: A methodological framework for the development of indicators of sustainable development. Int. J. Sustain. Dev. World Ecol. 1995, 2, 104-123. [CrossRef]

37. Choi, J.H.-J.; Graham, M. Urban food futures: ICTs and opportunities. Futures 2014, 62, 151-154. [CrossRef]

38. Vergragt, P.; Akenji, L.; Dewick, P. Sustainable production, consumption, and livelihoods: Global and regional research perspectives. J. Clean. Prod. 2014, 63, 1-12. [CrossRef]

39. Schubert, F.; Kandampully, J.; Solnet, D.; Kralj, A. Exploring Consumer Perceptions of Green Restaurants in the US. Tour. Hosp. Res. 2010, 10, 286-300. [CrossRef]

40. Pfeiffer, C.; Speck, M.; Strassner, C. What Leads to Lunch-How Social Practices Impact (Non-)Sustainable Food Consumption/Eating Habits. Sustainability 2017, 9, 1437. [CrossRef]

41. Rivera, M.; Shani, A. Attitudes and orientation toward vegetarian food in the restaurant industry: An operator's perspective. Int. J. Contemp. Hosp. Manag. 2013, 25, 1049-1065. [CrossRef]

42. Rabl, A.; de Nazelle, A. Benefits of shift from car to active transport. Transp. Policy 2012, 19, 121-131. [CrossRef]

43. Geels, F.W. A socio-technical analysis of low-carbon transitions: Introducing the multi-level perspective into transport studies. J. Transp. Geogr. 2012, 24, 471-482. [CrossRef]

44. Rojas-Rueda, D.; de Nazelle, A.; Teixidó, O.; Nieuwenhuijsen, M.J. Replacing car trips by increasing bike and public transport in the greater Barcelona metropolitan area: A health impact assessment study. Environ. Int. 2012, 49, 100-109. [CrossRef] [PubMed]

45. Mirosa, M.; Munro, H.; Mangan-Walker, E.; Pearson, D. Reducing waste of food left on plates: Interventions based on means-end chain analysis of customers in foodservice sector. Br. Food J. 2016, 118, 2326-2343. [CrossRef]

46. Quested, T.E.; Marsh, E.; Stunell, D.; Parry, A.D. Spaghetti soup: The complex world of food waste behaviours. Resour. Conserv. Recycl. 2013, 79, 43-51. [CrossRef]

47. Kallbekken, S.; Sælen, H. 'Nudging' hotel guests to reduce food waste as a win-win environmental measure. Econ. Lett. 2013, 119, 325-327. [CrossRef]

48. Doub, A.E.; Levin, A.; Heath, C.E.; LeVangie, K. Mobile app-etite: Consumer attitudes towards and use of mobile technology in the context of eating behaviour. J. Direct Data Digit. Mark. Pract. 2015, 17, 114-129. [CrossRef]

49. Sirieix, L.; Lála, J.; Kocmanová, K. Understanding the antecedents of consumers' attitudes towards doggy bags in restaurants: Concern about food waste, culture, norms and emotions. J. Retail. Consum. Serv. 2017, 34, 153-158. [CrossRef]

50. Van Lisanne, G.; van Erica, H.; van Hans, T. Causes \& Determinants of Consumers Food Waste; Project Report, EU Horizon 2020 REFRESH; Wageningen University and Research: Wageningen, The Netherlands, 2016; p. 44.

51. Grunert, K.G.; Hieke, S.; Wills, J. Sustainability labels on food products: Consumer motivation, understanding and use. Food Policy 2014, 44, 177-189. [CrossRef]

52. Marucheck, A.; Greis, N.; Mena, C.; Cai, L. Product safety and security in the global supply chain: Issues, challenges and research opportunities. J. Oper. Manag. 2011, 29, 707-720. [CrossRef]

53. Dillahunt, T.; Becker, G.; Mankoff, J.; Kraut, R. Motivating environmentally sustainable behavior changes with a virtual polar bear. In Proceedings of the Pervasive 2008 Workshop Proceedings, Sydney, Australia, 19-22 May 2008; Volume 8, pp. 58-62.

54. Cugelman, B. Gamification: What It Is and Why It Matters to Digital Health Behavior Change Developers. JMIR Serious Games 2013, 1, e3. [CrossRef] [PubMed]

55. Gagić, S. Restaurant Innovativeness: A Case Study of Vojvodina. Eur. J. Appl. Econ. 2016, 13, 57. [CrossRef]

56. Spence, C.; Piqueras-Fiszman, B. Technology at the dining table. Flavour 2013, 2, 16. [CrossRef]

57. Koo, M.; Krass, I.; Aslani, P. Consumer opinions on medicines information and factors affecting its use-An Australian experience. Int. J. Pharm. Pract. 2002, 10, 107-114. [CrossRef]

58. Smithson, J. Using and analysing focus groups: Limitations and possibilities. Int. J. Soc. Res. Methodol. 2000, 3, 103-119. [CrossRef]

(C) 2019 by the authors. Licensee MDPI, Basel, Switzerland. This article is an open access article distributed under the terms and conditions of the Creative Commons Attribution (CC BY) license (http://creativecommons.org/licenses/by/4.0/). 